\title{
Hepatic failure caused by acute fatty liver of pregnancy treated by orthotopic liver transplantation - A case report -
}

\section{Yun-Sic Bang, Daeun Ko, Sunyoung Lee, Seunghoon Lee, and Chunghyun Park}

Department of Aneshesiology and Pain Medicine, CHA Bundang Medical Center, CHA University, Seongnam, Korea
Received June 5, 2018

Revised June 29, 2018

Accepted July 6, 2018

\section{Corresponding author}

Chunghyun Park, M.D., Ph.D. Department of Anesthesiology and Pain Medicine, CHA Bundang Medical Center, CHA University, 59 Yatap-ro, Bundang-gu, Seongnam 13496, Korea

Tel: 82-31-780-5157

Fax: 82-31-701-9433

E-mail: anesthpark@cha.ac.kr ORCID

https://orcid.org/0000-0003-1916-6644
Acute fatty liver of pregnancy (AFLP) is unusual but can potentially progress to overwhelming liver failure, resulting in maternal and fetal death. AFLP is characterized by the accumulation of microvesicular fat within hepatocytes. We report the case of a 37-yearold woman at 36 weeks' gestation with a twin pregnancy who was admitted with the diagnosis of intrauterine fetal death of one baby. The patient showed profile of AFLP on her laboratory findings and underwent emergency cesarean section. Then she progressed to cryptogenic fulminant hepatic failure and underwent successful orthotopic liver transplantation on 9th day of admission. This case demonstrates that liver transplantation is a feasible therapeutic option for the treatment of patients with this condition.

Keywords: Acute liver failure; Cesarean section; Fatty liver; General anesthesia; Liver transplantation.
The dangerous conditions of pregnancy with the signs of liver failure include hyperemesis gravidarum, cholestatic syndromes of pregnancy, HELLP syndrome (hemolysis, elevated liver enzymes, low platelets), and the most rarely observed, acute fatty liver of pregnancy (AFLP) [1]. It is a rare complication of pregnancy but is potentially fatal for both mother and fetus. AFLP may begin innocuously with mild symptoms and liver-enzyme abnormalities, but, if left untreated, can progress to jaundice, liver failure, and death [2]. Early diagnosis on the basis of clinical assessment, prompt delivery of baby, intensive therapy by multidisciplinary team approach to detect deterioration are the keys to managing AFLP. We present a case of AFLP patient undertaken liver transplantation after cesarean section.

\section{CASE REPORT}

A previously healthy $64.5 \mathrm{~kg}$, 37-year-old $\mathrm{G}_{1} \mathrm{P}_{0}$ twin pregnant woman at 36 weeks of gestation complained of nausea, vomiting and abdominal pain for two days with sign of jaundice. Male fetus had no heartbeat, while female fetus had a heart rate of 140-145 beats/min on fetal ultrasound scan (US) and doppler. A week before, at her regular check-up, her blood test results were as follows: aspartate aminotransferase (AST), $778 \mathrm{IU} / \mathrm{L}$; alanine aminotransferase (ALT), 656 IU/L; total bilirubin, $2.17 \mathrm{mg} / \mathrm{dl}$; albumin $3.2 \mathrm{~g} / \mathrm{dl}$, glucose 91 $\mathrm{mg} / \mathrm{dl}$. Prothrombin time (PT) was $12.6 \mathrm{~s}$, and international normalized ratio (INR) was 1.12. On admission, blood test showed the following results: hemoglobin ( $\mathrm{Hb}), 14.1 \mathrm{~g} / \mathrm{dl}$; white blood cell count, 12,670 / $\mu \mathrm{l}$; platelet count, 304,000/ $\mu \mathrm{l}$; AST, $190 \mathrm{IU} / \mathrm{L} ; \mathrm{ALT}, 191 \mathrm{IU} / \mathrm{L} ; \mathrm{Na}^{+}, 132 \mathrm{mEq} / \mathrm{L} ; \mathrm{K}^{+}, 6.4 \mathrm{mEq} /$

This is an Open Access article distributed under the terms of the Creative Commons Attribution Non-Commercial License (http://creativecommons.org/licenses/by-nc/4.0) which permits unrestricted non-commercial use, distribution, and reproduction in any medium, provided the original work is properly cited. 
L; $\mathrm{Cl}^{-}, 98 \mathrm{mEq} / \mathrm{L}$; total bilirubin, $13.16 \mathrm{mg} / \mathrm{dl}$; albumin, $3.0 \mathrm{~g} /$ dl; glucose, $81 \mathrm{mg} / \mathrm{dl}$; blood urea nitrogen, $16.1 \mathrm{mg} / \mathrm{dl}$; creatinine, $2.1 \mathrm{mg} / \mathrm{dl}$; D-Dimer was > 10,000.0 ng/ml, PT/partial prothrombin time (PTT) was uncheckable. Serologic tests for viral hepatitis A, B, and $\mathrm{C}$ were all negative. Arterial blood gas analysis showed $\mathrm{pH}$ 7.338, $\mathrm{pCO}_{2} 23.7 \mathrm{mmHg}, \mathrm{pO}_{2} 176.0$ $\mathrm{mmHg}, \mathrm{HCO}_{3}{ }^{-} 12.4 \mathrm{mmol} / \mathrm{L}$, and base excess (BE) -11.6 $\mathrm{mmol} / \mathrm{L}$. Her clinical diagnosis was AFLP and disseminated intravascular coagulation (DIC). Emergency cesarean section was considered necessary to avoid death of living fetus and rapid progression of DIC. On arrival of the operating room, her blood pressure was $120 / 78 \mathrm{mmHg}$, and heart rate was 120 beats/min. She was alert and oriented. Arterial cannulation was performed at the left radial artery. Rapid sequence induction of general anesthesia was achieved with intravenous (IV) propofol $100 \mathrm{mg}$ and succinylcholine $70 \mathrm{mg}$, and the trachea was easily intubated. Maintenance of anesthesia was accomplished with rocuronium $30 \mathrm{mg}$ IV, 50\% oxygen, 50\% nitrous oxide and an end-tidal concentration of sevoflurane 0.5 volume \%. Crystalloid was loaded via right external jugular vein. Sufentanil $10 \mu \mathrm{g}$ IV and midazolam $3 \mathrm{mg}$ IV were administered after delivery of a live female infant at $5 \mathrm{~min}$ after induction. Apgar scores were 2, 5, and 8 at $1 \mathrm{~min}, 5 \mathrm{~min}$, and $10 \mathrm{~min}$ respectively. One-minute Apgar score was 2 (pulse 1 point respiration 1 point). The pediatrician immediately performed intubation. The Apgar score was gradually restored with oxygen supply. The baby was transported to neonate intensive care unit with ambu bagging. Oxytocin $20 \mathrm{IU}$ was mixed into crystalloid. Uterine contraction was poor, and surprostone $100 \mu \mathrm{g}$ was mixed into crystalloid as well. After delivery of both babies, her blood pressure suddenly dropped under $80 / 40 \mathrm{mmHg}$. Sevoflurane was lowered to 0.3 volume $\%$ and norepinephrine was continuously infused to maintain blood pressure. Persistent metabolic acidosis was corrected with ventilation and sodium bicarbonate. Three units of fresh frozen plasma (FFP), two units of packed red blood cell (PRBC) and 2,000 ml of lactated Ringer's solution were administered. The urine output was $200 \mathrm{ml}$, and the estimated blood loss was $800 \mathrm{ml}$. No clot was initially seen in the surgical field. Adequate hemostasis was achieved by the end of surgery. The patient was awakened, reversed with glycopyrrolate $0.2 \mathrm{mg}$ IV, pyridostigmine $10 \mathrm{mg}$ IV and extubated after she was able to follow commands. She showed clear mental status. However, her vital signs were unstable. Therefore, she was sent to intensive care unit after central venous catheterization via right external jugular vein using Seldinger technique.

On the first postoperative day (POD \#1), massive vaginal bleeding was observed. Thus, emergency uterine artery embolization was performed and 15 units of FFP, 20 units of PRBC and 20 units of platelet concentrate (PC) were administered. Oxygen saturation fell to $88 \%$ and pulmonary congestion was found on chest X-ray. She was diagnosed with transfusion related acute lung injury due to massive transfusion. On POD \#2, systolic blood pressure was decreased to 80 mmHg and the patient showed tachycardia (over 140 beats/ $\mathrm{min}$ ) with signs of abdominal distension and increased rigidity. Abdominal-Pelvis CT scan revealed active bleeding from the right lower rectus abdominis. A small branch of right inferior epigastric artery embolization was done. Her abdominal ultrasound scan showed ascites and diffusely increased liver parenchymal echogenicity due to fatty liver. Oxygen saturation was consistently below $90 \%$ although oxygen was supplied with mask. As increased work of breathing was noted, she was intubated and mechanical ventilation was required. On POD \#5, the patient progressed to hepatic deterioration; demonstrating delirium symptoms with stage 3 hepatic coma. She was transferred to the department of transplantation and liver surgery, and scheduled for orthotopic liver transplantation (OLTx). Her Child-Turcotte-Pugh score was 11 and the Model for End-Stage Liver Disease score was 33. She was registered for a liver transplant recipient as "status 1 ", representing that the patient was at the risk of imminent death. POD \#8, continuous renal replacement therapy was started due to severe renal impairment. Emergency OLTx was performed with a cadaver liver harvested from the donor of the same blood group.

She came to the operation room under intubated state. Desflurane, $40 \%$ of oxygen with mixture of air, remifentanil and cis-atracurium were administered continuously. MultiLumen Access Catheters (MAC) was catheterized at the right internal jugular vein. Swan-Ganz catheter was inserted through MAC. Rapid infuser system was prepared for large volume replacement and transesophageal echocardiography was monitored throughout general anesthesia. The operation started 70 min after induction of anesthesia. Norepinephrine was infused to maintain blood pressure between 120-140 $\mathrm{mmHg}$ (systolic) before anhepatic phase. After reperfusion, the blood pressure dropped to $90 \mathrm{mmHg}$, and pulse went 
down to 40. After a bolus injection of epinephrine $100 \mu \mathrm{g}$ and atropine $0.5 \mathrm{mg}$, blood pressure and pulse were normalized. The patient maintained stable vital signs throughout the surgery. During operation, 5 units of FFP, 5 units of PRBC, 20 units of PC, 1,500 ml of 5\% albumin, $20 \%$ mannitol $200 \mathrm{ml}$ and 4,200 $\mathrm{ml}$ of crystalloid were administered. Glucose, $\mathrm{KCl}$, and $\mathrm{CaCl} 2$ were added intermittently based on arterial blood gas analysis. She was sent to ICU for post-operative care. After successful OLTx, patient status was improved. She was discharged from the hospital on the 25th hospital day (Table $1)$.

\section{DISCUSSION}

It has been estimated that about $3 \%$ of all pregnant women present abnormal activities of hepatic enzymes, reflecting the functional disturbances of parenchymal liver cells. Dangerous conditions include preeclampsia with signs of liver failure, liver insufficiency accompanying the first phase of gravity toxicosis with massive vomiting (hyperemesis gravidarum), cholestatic syndromes of pregnancy, HELLP syndrome and AFLP which is the most rarely observed one [1]. AFLP was first described in 1934 by Stander and Cadden [3] as "acute yellow atrophy of the liver". It is characterized by the accumulation of microvesicular fat within hepatocytes [4]. The incidence of AFLP is estimated to be 1 in 10,000-15,000 pregnancies with a mortality of $10-20 \%$ [4]. Biochemical lesion may be either an isolated deficiency of long-chain 3-hydroxy acyl-CoA dehydrogenase (LCHAD) or a complete deficiency of a trifunctional protein that catalyzes the last three steps of mitochondrial fatty acid oxidation. Deficiency of LCHAD has been found in children of women who have AFLP or HELLP syndrome during pregnancy. However, not all women carrying fetuses with LCHAD deficiency or trifunctional protein deficiency have liver disease. LCHAD metabolites produced by a fetus with this defect may accumulate and overwhelm the mitochondrial oxidation machinery in a heterozygous mother who is already under metabolic stress due to in-

Table 1. Laboratory Findings of the Patient

\begin{tabular}{|c|c|c|c|c|c|c|c|c|}
\hline & \multicolumn{5}{|c|}{$\mathrm{C} / \mathrm{Sec}$} & \multicolumn{3}{|c|}{ LT } \\
\hline & -1 week & Pre OP & POD \#1 & POD \#2 & POD \#8 & POD \#1 & POD \#7 & Normal \\
\hline AST/ALT (IU/L) & $778 / 656$ & $190 / 191$ & $75 / 66$ & $32 / 19$ & $38 / 21$ & $1,820 / 1,130$ & $30 / 82$ & $0-40 / 0-41$ \\
\hline ALP (IU/L) & 739 & 1,985 & 687 & 224 & 295 & 261 & - & $35-129$ \\
\hline Bilirubin (mg/dl) & 2.17 & 13.16 & 6.93 & 5.91 & 22.38 & 10.98 & 4.98 & $0-1.2$ \\
\hline Total cholesterol (mg/dl) & 228 & 205 & 108 & 125 & - & 68 & - & $115-230$ \\
\hline $\mathrm{TG}(\mathrm{mg} / \mathrm{dl})$ & 209 & 210 & 100 & 67 & - & 120 & - & $50-200$ \\
\hline $\mathrm{Na}^{+}(\mathrm{mEq} / \mathrm{L})$ & 137 & 132 & 140 & 146 & 143 & 142 & 136 & $135-145$ \\
\hline $\mathrm{K}^{+}(\mathrm{mEq} / \mathrm{L})$ & 4.8 & 6.4 & 3.7 & 3.8 & 3.5 & 3.6 & 3.7 & $3.5-5.1$ \\
\hline $\mathrm{Cl}^{-}(\mathrm{mEq} / \mathrm{L})$ & 105 & 98 & 102 & 103 & 104 & 105 & 108 & $98-110$ \\
\hline Albumin (g/dl) & 3.2 & 3.0 & 2.5 & 3.7 & - & 3.3 & 2.9 & $3.5-5.2$ \\
\hline BUN (mg/dl) & 9.6 & 16.1 & 12.5 & 18.1 & 21 & 46.3 & 21.3 & $5-20$ \\
\hline $\mathrm{Cr}(\mathrm{mg} / \mathrm{dl})$ & 0.8 & 2.1 & 1.7 & 2 & 2.1 & 1.5 & 0.8 & $0.5-0.9$ \\
\hline Glucose (mg/dl) & 91 & 81 & 124 & 75 & - & 152 & 129 & $74-109$ \\
\hline $\mathrm{PT}(\mathrm{s})$ & 12.6 & UC & 155.9 & 16.2 & 22 & 15.2 & 12.5 & $9.5-12.5$ \\
\hline $\mathrm{PTT}(\mathrm{s})$ & 33.1 & UC & $>400$ & 34.1 & 42.9 & 38.1 & 25.7 & $26.7-38.1$ \\
\hline INR & 1.12 & UC & 13.21 & 1.44 & 1.94 & 1.35 & 1.11 & $0.88-1.11$ \\
\hline Fibrinogen (mg/dl) & - & UC & 86 & 197 & 238 & - & - & $251.8-514.1$ \\
\hline Ammonia $(\mu \mathrm{g} / \mathrm{dl})$ & - & - & 85 & 102 & 157 & 56 & 80 & $15-100$ \\
\hline Hemoglobin (g/dl) & 11.1 & 14.1 & 7.2 & 8.9 & 11.8 & 10.3 & 10.4 & $11-16$ \\
\hline Platelet $\left(\times 10^{3} / \mu \mathrm{l}\right)$ & 249 & 304 & 126 & 83 & 55 & 86 & 216 & $150-380$ \\
\hline $\mathrm{pO}_{2}(\mathrm{mmHg})$ & - & 176.0 & 60.3 & 48.2 & 139.5 & 88.9 & - & $80-100$ \\
\hline $\mathrm{pCO}_{2}(\mathrm{mmHg})$ & - & 23.7 & 41.3 & 38.9 & 26.7 & 32.7 & - & $35-45$ \\
\hline $\mathrm{pH}$ & - & 7.338 & 7.415 & 7.408 & 7.367 & 7.498 & - & \\
\hline Base excess (mmol/L) & - & -11.6 & -0.5 & -0.6 & -8.7 & 1.9 & - & $-3-3$ \\
\hline
\end{tabular}

PreOP: preoperative, C/Sec: caesarean section, POD: postoperative day, LT: liver transplantation, AST: aspartate aminotransferase, ALT: alanine aminotransferase, ALP: alkaline phosphatase, TG: triglyceride, BUN: blood urea nitrogen, Cr: creatinine, PT: prothrombin time, PTT: partial thromboplastin time, INR: international normalized ratio, UC: uncheckable. 
creased demand for fatty acid oxidation in latter stages of pregnancy [5].

Women carrying more than one fetus or in their first pregnancy are affected the most often. Symptoms begin at a mean of 36 weeks of gestation [6]. Our patient had risk factors such as nulliparity and twin pregnancies. She presented gastric discomfort as the first symptom at 36 weeks of gestation. The patient should demonstrate at least six of the Swansea criteria for AFLP. Criteria include nausea, abdominal pain, polydipsia/polyuria, encephalopathy, hypoglycemia, leukocytosis, ascites or bright liver on ultrasound scan, elevated aminotransferases, elevated bilirubin, elevated ammonia, renal impairment, coagulopathy, and microvesicular steatosis on liver biopsy [7]. Although liver biopsy is the definitive technique for confirming the diagnosis, it is often impossible to perform a liver biopsy immediately in pregnant patients with severe coagulation abnormalities. Clinical findings and laboratory data are essential for the diagnosis. However, liver biopsy is not necessary for the diagnosis [8]. Our patient had eight clinical findings of the criteria. Her ultrasound scan showed ascites and diffusely increased liver parenchymal echogenicity due to fatty liver. Clinical presentation was typical with malaise, nausea and vomiting, abdominal pain and rarely, encephalopathy. Prolongation of laboratory clotting tests is an early feature. Immediate delivery is the key to manage AFLP. The condition may deteriorate suddenly with rapid progression to fulminant hepatic failure, hepatic coma, DIC, gastrointestinal hemorrhage, renal failure, and occasional acute pancreatitis. Resolution of AFLP can only begin after delivery. The highest frequency of survival for both mother and baby has been reported when delivery is made by cesarean section or induced [9]. In our case, the patient progressed rapidly to DIC, fulminant hepatic failure, hepatic coma, and renal failure after delivery of the baby. Her condition might have already started to deteriorate when she was admitted to hospital. It might be the cause of the death of the baby boy.

An anesthesiologist should be part of a multidisciplinary team in time of crisis. One dilemma encountered by an anesthesiologist involves the decision that must be made about the method of anesthesia. General anesthesia has potentially adverse effects on hepatic encephalopathy while regional anesthesia is associated with risk of coagulopathy. Postoperative analgesia may also be complicated by impaired renal and hepatic function [10]. The patient's PT and PTT were un- checkable. Thus, we administered a general anesthetic rather than risking a delay for correcting coagulopathy to provide a regional block. This patient had no evidence of neurologic dysfunction. However, careful neurologic monitoring is essential for AFLP management. Documentation of mental status before and after general anesthesia is crucial [11]. We inserted the central venous pressure catheter via right external jugular vein instead of the internal jugular vein because of the risk of bleeding tendency.

With aggressive supports with blood products, it may be difficult to judge functional hepatic recovery using PT or PTT. Moreover, changes in plasma albumin levels reflect neither acute liver dysfunction nor recovery. Acute parenchymal liver disease is commonly associated with increased plasma triglycerides, decreased cholesterol esters, and abnormal lipoproteins that might be sensitive markers for hepatic injury and recovery. Cholesterol level is an acceptable marker of acute functional hepatic recovery [11].

Early diagnosis and intensive therapy in multidisciplinary centers where cooperation among gynecologists/obstetricians, hepatologists, anesthesiologists, and surgeons is possible can improve results of AFLP treatment. AFLP is a severe disease with high maternal (18\%) and fetal (23\%) mortality [7]. The aggressive therapy requires strict correction of fluid-electrolytes imbalance, hypoglycemia, treatment for encephalopathy, and corrections of coagulation disorders. Frequently observed renal failure may require renal dialysis. The most difficult complication to treat is the consequence of coagulation diathesis [12]. Therefore, all AFLP patients should be monitored intensively immediate after delivery.

OLTx for treatment of hepatic failure resulting from AFLP remains controversial regarding its efficacy. Most centers reserve OLTx for patients with complicated and advanced AFLP who do not improve with maximally intensive therapy [13]. This case was typical for AFLP, including clinical picture, laboratory data, coagulation profile, and hemorrhagic complications. To the best of our knowledge, this is the first case report of anesthesia in a Korean patient with AFLP. The decision for OLTx was based on her worsening clinical condition despite the most sophisticated intensive care measures. The favorable outcome of transplantation seems to justify our decision. Some authors [14] have stressed that the syndrome (despite its dramatic clinical course) is a reversible phenomenon and that termination of pregnancy usually ends the 
illness. Such cases have been described in the literature [15]. In conclusion, early diagnosis based on clinical assessment, prompt delivery of baby, and intensive therapy by multidisciplinary team approach are recommended to detect deterioration and OLTx should be considered if a patient's clinical course is similar to our case.

\section{CONFLICTS OF INTEREST}

No potential conflict of interest relevant to this article was reported.

\section{ORCID}

Yun-Sic Bang: https://orcid.org/0000-0002-0930-4313

Daeun Ko: https://orcid.org/0000-0001-5731-2249

Sunyoung Lee: https://orcid.org/0000-0003-4273-2202

Seunghoon Lee: https://orcid.org/0000-0001-9843-5472

\section{REFERENCES}

1. Remiszewski P, Pawlak J, Skwarek A, Grzelak I, Patkowski W, Grodzicki M, et al. Orthotopic liver transplantation for acute liver failure resulting from "acute fatty liver of pregnancy". Ann Transplant 2003; 8: 8-11.

2. Knox TA, Olans LB. Liver disease in pregnancy. N Engl J Med 1996; 335: 569-76.

3. Stander HJ, Cadden JF. Acute yellow atrophy of the liver in pregnancy. Am J Obstet Gynecol 1934; 28: 61-9.

4. Pockros PJ, Peters RL, Reynolds TB. Idiopathic fatty liver of pregnancy: findings in ten cases. Medicine (Baltimore) 1984; 63: 1-11.

5. Treem WR, Shoup ME, Hale DE, Bennett MJ, Rinaldo P, Millington DS, et al. Acute fatty liver of pregnancy, hemolysis, elevated liver enzymes, and low platelets syndrome, and long chain 3-hydroxyacyl-coenzyme A dehydrogenase deficiency. Am J Gastroenterol 1996; 91: 2293-300.

6. Riely CA. Acute fatty liver of pregnancy. Semin Liver Dis 1987; 7 : 47-54.

7. Ahmed KT, Almashhrawi AA, Rahman RN, Hammoud GM, Ibdah JA. Liver diseases in pregnancy: diseases unique to pregnancy. World J Gastroenterol 2013; 19: 7639-46.

8. Riely CA, Latham PS, Romero R, Duffy TP. Acute fatty liver of pregnancy. A reassessment based on observations in nine patients. Ann Intern Med 1987; 106: 703-6.

9. Brown MA, Passaris G, Carlton MA. Pregnancy-induced hypertension and acute fatty liver of pregnancy: atypical presentations. Am J Obstet Gynecol 1990; 163: 1154-6.

10. Gregory TL, Hughes S, Coleman MA, De Silva A. Acute fatty liver of pregnancy; three cases and discussion of analgesia and anaesthesia. Int J Obstet Anesth 2007; 16: 175-9.

11. Holzman RS, Riley LE, Aron E, Fetherston J. Perioperative care of a patient with acute fatty liver of pregnancy. Anesth Analg 2001; 92: 1268-70.

12. Rahman TM, Wendon J. Severe hepatic dysfunction in pregnancy. QJM 2002; 95: 343-57.

13. Ockner SA, Brunt EM, Cohn SM, Krul ES, Hanto DW, Peters MG. Fulminant hepatic failure caused by acute fatty liver of pregnancy treated by orthotopic liver transplantation. Hepatology 1990; 11: 59-64.

14. Castro MA, Fassett MJ, Reynolds TB, Shaw KJ, Goodwin TM. Reversible peripartum liver failure: a new perspective on the diagnosis, treatment, and cause of acute fatty liver of pregnancy, based on 28 consecutive cases. Am J Obstet Gynecol 1999; 181: 389-95.

15. Doepel M, Backas HN, Taskinen EI, Isoniemi HM, Höckerstedt KA. Spontaneous recovery of post partus liver necrosis in a patient listed for transplantation. Hepatogastroenterology 1996; 43: 1084-7. 